Article

\title{
Effect of Exposure Conditions on the Interfacial Bond Properties of SS400 Plate Coated with Various Epoxy Resins
}

\author{
Sungwon Kim $₫$, Hyemin Hong, Jun Kil Park, Sangmin Park, Seoung Ik Choi and \\ Min Ook Kim *iD \\ Coastal Development and Ocean Energy Research Center, Korea Institute of Ocean Science and Technology, 385, \\ Haeyang-ro, Yeongdo-gu, Busan 49111, Korea; swkim@kiost.ac.kr (S.K.); hyeminhong@kiost.ac.kr (H.H.); \\ jkpark@kiost.ac.kr (J.K.P.); sangmin@kiost.ac.kr (S.P.); sichoi@kiost.ac.kr (S.I.C.) \\ * Correspondence: minookkim@kiost.ac.kr; Tel.: +82-51-664-3520
}

Received: 16 October 2020; Accepted: 24 November 2020; Published: 28 November 2020

\begin{abstract}
This study aims to investigate the effects of different exposure conditions on the interfacial bond between steel plates and epoxy resin coatings at early ages. Test variables include the epoxy resin types, exposure conditions, exposure periods, and coating equipment. The selected epoxy resins were applied to prepared steel plates and cured at each exposure condition for 7, 28, 56, or 91 days, and the pull-off bond strength and coating thickness were measured. Scanning electron microscopy (SEM) images were obtained to study the interfacial bond for some representative coatings. Three different exposure conditions (indoors and actual marine environment) were considered in this study. This study is also focusing on the improvement of previously developed underwater coating equipment and evaluating the performance. Experiments were conducted to evaluate the performance of the improved equipment types under different environmental conditions: indoors (tap water and seawater) and outdoor conditions. The improved equipment types were confirmed to be effective for underwater coating and easier to use than the previous equipment under real sea conditions. The experimental results also confirmed that the bond strength of the coating decreased as the curing time increased.
\end{abstract}

Keywords: exposure condition; interfacial bond; steel plate; epoxy resin; equipment for underwater coating

\section{Introduction}

Surface protection of marine and coastal structures is critical, especially for the steel structures since they are suffering from the chloride and sulfate attacks from the seawater [1-12]. Corrosion issues always exist for such structures due to the salt present in seawater, and the structural safety may be threatened by attached marine organisms [1-5]. The systematic repair (e.g., surface coating) is therefore important to save the maintenance cost and guarantee the designed service life of structures [6-12]. For instance, the installation rate of offshore windfarm structures is expected to increase until 2030 [13], and the maintenance costs for these structures can be as high as $31.3 \%$ of the total cost [14]. Thus, maintenance is important and represents a large proportion of the cost for the construction of offshore structures. In addition to wind power, other offshore structures such as marine structures and oil and gas drilling structures are currently in operation or being planned for construction [15]. This trend confirms again the importance of maintenance for offshore structures and the high growth potential of the maintenance sector. Various studies have focused on developing maintenance methods for offshore structures. Kanwal et al. [16] applied hexamethylene diisocyanate 
(HMDI) for preventing the surface corrosion of 304 stainless steel. Ates [17] reviewed the literature on using polymer coatings to prevent the surface corrosion of structures.

Surface coating technology with using epoxy resins has been widely utilized in steel structures for the surface repair and to prevent further corrosion [18-28]. Verma et al. [29] and Atta et al. [30] developed epoxy materials that can be used in the marine environments. Specifically, Atta et al. [30] used a new solvent-free epoxy and polyamine hardener based on cardanol derived from cashew nut shell liquid as a renewable and sustainable alternative to epoxy coatings to protect steel from corrosion. Their poly-functional epoxy resin was based on epoxidized cardanol hydroxyl, unsaturated alkyl substituents (CNE), and polyamine cardanol hardener (CPA). The developed epoxy material cured rapidly at low temperatures within 30-120 min. They derived the optimal mixing ratio of CNE/CPA to maximize coating performance parameters such as the bond strength, hardness, impact resistance, and corrosion resistance.

In our previous studies [11,12], two types of coating equipment that can be utilized in underwater conditions were developed and their performance was evaluated (see Figure 1). However, previously developed coating equipment had several problems that can significantly influence the coating efficiency compared to existing equipment (e.g., conventional roller). Furthermore, previous experiments and measurements were carried out in constant laboratory conditions rather than at the site test considering actual marine environments.

(a)
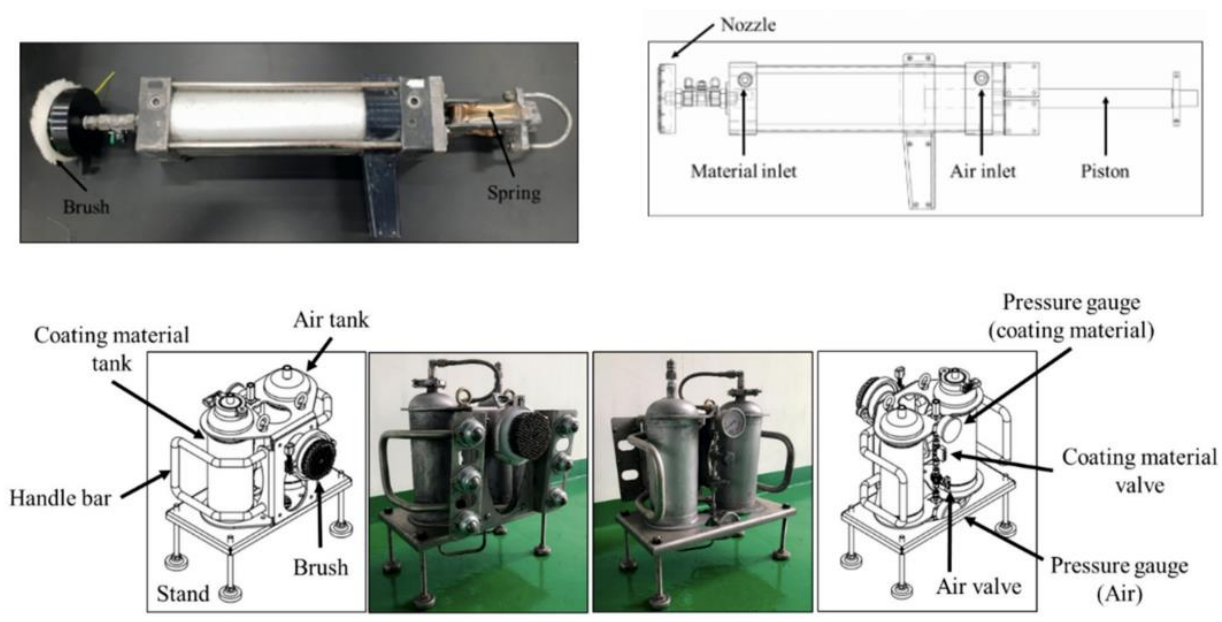

Figure 1. Two coating equipment previously developed (a) gun-type equipment using spring stiffness (EQ_G) and (b) two-handed-type equipment using air pressure (EQ_H) (Adapted with permission from ref. [12] 2019 by Kim et al., MDPI).

In this regard, it is necessary to explore some important factors that might affect the interfacial bond of coated steel plates, including how these factors affect the bond strength and debonding of the coated section. These factors may include the type of epoxy resin, exposure condition, exposure period, and coating method. To this end, an experimental program was designed and comprehensive experimental study was carried out to clarify the effect of different exposure conditions on the interfacial bond properties between SS400 (SS is the abbreviation of Steel Structure, 400 means that the tensile strength is $\geq 400 \mathrm{MPa}$ ) plate and commercially available epoxy resins. Specifically, the effects of three different exposure conditions (laboratory conditions with using tap water or seawater, and actual marine environment) on the measured bond strength and coating thickness were examined. The detailed test variables include the epoxy resin types, exposure conditions, exposure periods, and coating equipment. The present study also focused on addressing the problems of the previously developed equipment to improve the coating performance. This study provides valuable data on the bond performance of epoxy coated steel plates cured in conditions of an actual marine environment. 


\section{Experimental Investigation}

\subsection{Epoxy Resins}

All coating materials were epoxy-based two-component systems mixing a main resin and hardener. Three different epoxy resins that showed good adhesion from our previous studies [11,12] were selected and Table 1 presents detailed material properties. The nomenclature for each epoxy resin was determined as M1 (RS500P, Chemco, Coatbridge, Scotland, UK), M2 (Alocit 28.15, A\&E Group, Shah Alam, Malaysia), M3 (Alocit 28.14, A\&E Group, Shah Alam, Malaysia), respectively. The main difference between each material is that M1 is usually applied for steel structures under conventional air conditions while both M2 and M3 were originally developed for steel and concrete structures subjected to the extreme marine environment. The mixing ratios provided by the manufacturer were applied. Table 1 also includes other notations (C1, C2, C4, S2, S4, and S5) that correspond to our previous studies for the purpose of comparison.

Table 1. Material properties of selected epoxy resins.

\begin{tabular}{|c|c|c|c|c|c|}
\hline $\begin{array}{l}\text { Epoxy Resins } \\
\text { (Nomenclature) }\end{array}$ & $\begin{array}{c}\text { Bond Strength } \\
(\mathrm{MPa})\end{array}$ & $\begin{array}{l}\text { Density } \\
\left(\mathrm{g} / \mathrm{cm}^{3}\right)\end{array}$ & $\begin{array}{c}\text { Working } \\
\text { Time (min) }\end{array}$ & Won et al. [11] & Kim et al. [12] \\
\hline M1 & 16.6 & $1.60 \pm 0.1$ & 30 at $30^{\circ} \mathrm{C}$ & C4 & S2 \\
\hline M2 & 6.9 & 1.55 & $45-60$ at $20^{\circ} \mathrm{C}$ & $\mathrm{C} 2$ & S4 \\
\hline M3 & 17.0 & 1.82 & $45-60$ at $20^{\circ} \mathrm{C}$ & $\mathrm{C} 1$ & S5 \\
\hline
\end{tabular}

\subsection{Exposure Conditions and Periods}

A circular fiber-reinforced plastic (FRP) water tank with a diameter of $2.5 \mathrm{~m}$ and height of $1.5 \mathrm{~m}$ was manufactured for the laboratory experiment, as shown in Figure 2. Laboratory experiments were conducted not only in tap water but also in seawater. The water level was set to $1.2 \mathrm{~m}$, which was higher than in the previous experiment, and a specimen support was installed, as shown in Figure 2c. This made it possible to work facing the front to reproduce the situation where the wall of the structure is being repaired rather than the floor. After the experiments in tap water, the tank was drained and refilled to the same level with seawater taken from the coast of Tongyeong, Korea. The steel specimens in the test were made of SS400 with dimensions of $300 \mathrm{~mm} \times 300 \mathrm{~mm} \times 3 \mathrm{~mm}$. The coated specimens were placed in a curing water bath and stored for $7,28,56$, or 91 days under either water condition.

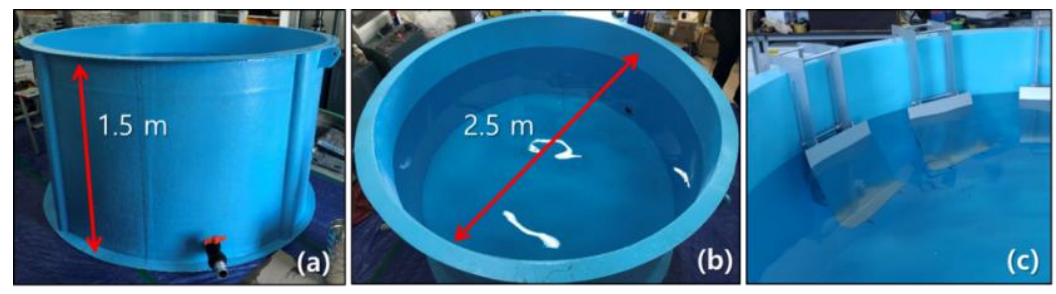

Figure 2. Circular fiber-reinforced plastic (FRP) water tank and specimen support (a) height of the tank, (b) diameter of the tank, and (c) specimen support.

The site tests at the actual marine environment were conducted using the same equipment as those used in the indoor experiment. The tests took place nearby the Geoje's SsangGeon breakwaters of Gyeongnam, Korea. A mounting frame for curing the specimens was fabricated and installed on the seafloor at a depth of approximately $8 \mathrm{~m}$. The coating materials were applied to steel plates at a depth of about $3 \mathrm{~m}$ near the breakwater, where the seafloor had a flat bottom. Then, the coated steel plates were mounted on the installed frame and stored. The plates were made of the same steel material as in the indoor test with the same dimensions. Figure 3 shows photos taken in a real subsea environment. The curing periods under the actual marine environment were $7,28,56$, and 91 days, as in the indoor 
experiment. After each curing period, a specimen was recovered from the site, and the bond strength and coating thickness were measured.
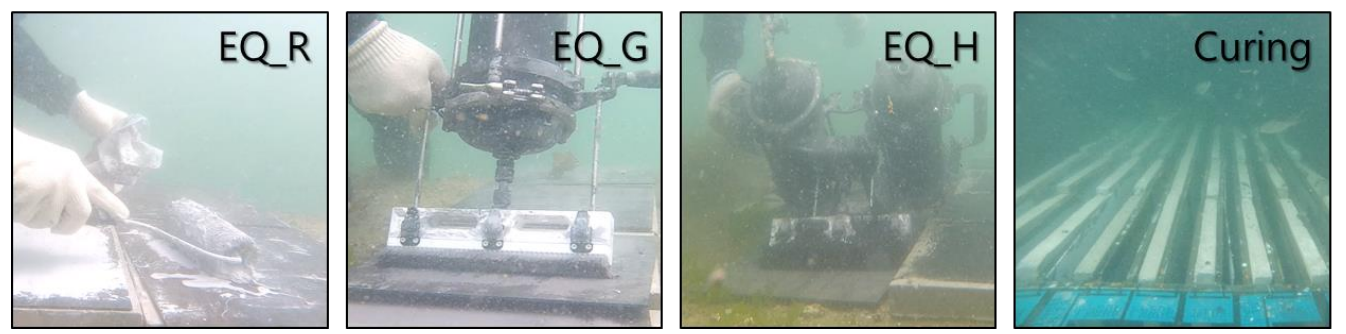

Figure 3. Underwater coating and curing in a real marine environment.

\subsection{Coating Equipment}

Three types of equipment were used in this study: roller (EQ_R), gun-type (EQ_G), and two-handed-type (EQ_H). EQ_R was used as a control, similar to Kim et al. [12]. The roller had a length of $180 \mathrm{~mm}$ and diameter of approximately $70 \mathrm{~mm}$, and it was made of a regular synthetic bristle (see Figure 4). EQ_G and EQ_H are improved versions of the previously developed equipment [12], which were inconvenient to use owing to their heavy self-weight and difficulty with cleaning. One of the biggest problems was that the brush used for coating was too stiff or weak. Other problems were also addressed; the details of the changes to each equipment type are described below.

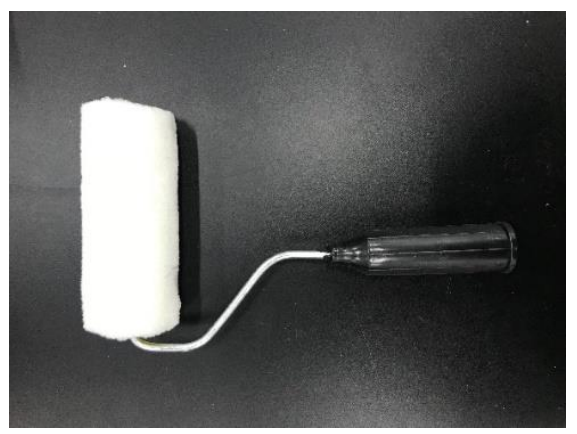

Figure 4. EQ_R (ordinary roller).

\subsubsection{EQ_G}

A stiff spring was used for the previous EQ_G [19], but this was replaced with a threaded shaft and unidirectional pulley to push the piston. The previous EQ_Q was heavy, and the handle was uncomfortable to use. To solve these problems, the equipment was made from polytetrafluoroethylene (PTFE). Two handles were placed on the nozzle side, and a shoulder strap was attached to increase the functionality. For the brush, the wool was too weak to tear off the coating, which was made of highly sticky material. To improve upon this, a brush with densely arranged fine Teflon fibers was used. To clean the previous equipment, a large amount of solvent was required for repeated washing operations because of the high adhesion of the coating material to the equipment after use. The improved equipment was made from Teflon so that the coating material would not stick to the equipment, which significantly reduced the time and amount of solvent required for cleaning. Table 2 summarizes the problems of the previous equipment and the improvements and presents the appearance of the new equipment. 
Table 2. Improvements to EQ_G.

\begin{tabular}{|c|c|c|c|}
\hline \multirow[t]{4}{*}{ Previous EQ_G } & Problem & Improvement & EQ_G \\
\hline & $\begin{array}{l}\text { 1. Pulled out wool brush } \\
\rightarrow \text { hard to treat a surface }\end{array}$ & 1. Apply a new PTFE brush & \\
\hline & $\begin{array}{l}\text { 2. Adhesion of coating } \\
\text { material between piston } \\
\text { and equipment body } \\
\rightarrow \text { hard to wash }\end{array}$ & $\begin{array}{l}\text { 2. Use PTFE } \\
\text { coating material }\end{array}$ & \\
\hline & $\begin{array}{l}\text { 3. Only one angled grip } \\
\rightarrow \text { hard to handle }\end{array}$ & $\begin{array}{l}\text { 3. Attach dual grips } \\
\text { and a strap }\end{array}$ & \\
\hline & $\begin{array}{l}\text { 4. Frequently malfunctioning } \\
\text { spring } \rightarrow \text { hard to jet }\end{array}$ & $\begin{array}{l}\text { 4. Replace the spring type } \\
\text { with a screw type and } \\
\text { apply a one-way pulley }\end{array}$ & \\
\hline
\end{tabular}

Figure 5 shows the Teflon brush, which is easily cleaned and reusable. It consists of two bodies, and it can be separated from the equipment body. The connection part connects the brush to the equipment body, and the brush part has a number of PTFE fibers arranged. A nut connecting the discharge port and brush is located at the center of the connection part. Holes were drilled on both sides to improve the connection with the equipment body. Six clips connect the connection part and brush part, and sealing rubber is placed between the two parts to minimize the gap when they are fastened together.

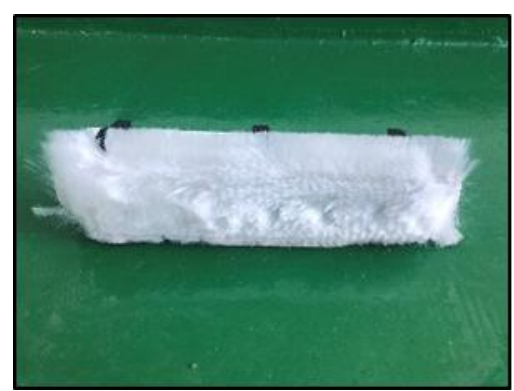

(a)

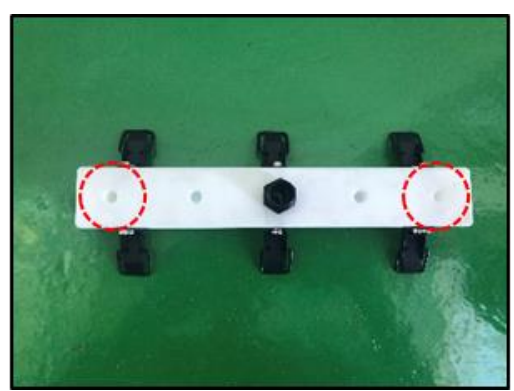

(b)

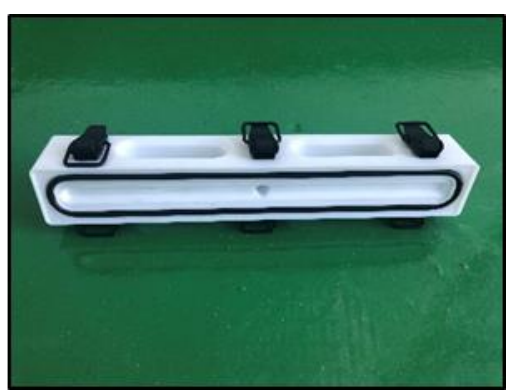

(c)

Figure 5. Teflon brush (a) Teflon fiber, (b) connection part between equipment and the brush assembly, and (c) connection part between brush body and Teflon fiber.

\subsubsection{EQ_H}

The previous EQ_H was difficult to use in indoor experiments because of its heavy self-weight, similar to EQ_G. In this study, the weight was reduced by modifying the material and design. The upper and lower parts of the coating material tank can open and close at a location with a large diameter, and Teflon was used to improve the convenience of material injection and cleaning after use. The connection between the oxygen tank and material tank was replaced with a flexible tube made of PTFE to reduce clogging and facilitate replacement. The gauges displaying the air pressure and pressure of the material tank were relocated to improve their visibility. The parts for connecting the equipment body and brush were the same as those used for EQ_G so that the same brush could be used. Table 3 summarizes the problems of the previous EQ_H and the improvements and presents the appearance of the new equipment. 
Table 3. Improvements to EQ_H.

\begin{tabular}{|c|c|c|c|}
\hline Previous EQ_H & Problem & Improvement & EQ_H \\
\hline & $\begin{array}{l}\text { 1. Adhesion of coating } \\
\text { materials and small inlet } \\
\text { diameter } \rightarrow \text { hard to } \\
\text { wash inside }\end{array}$ & $\begin{array}{l}\text { 1. Use } \\
\text { polytetrafluoroethylene } \\
\text { (PTFE) coating material } \\
\text { and bigger inlet diameter }\end{array}$ & \\
\hline & $\begin{array}{l}\text { 2. Stiff material brush } \rightarrow \\
\text { hard to treat surface }\end{array}$ & $\begin{array}{l}\text { 2. Apply a new PTFE } \\
\text { brush }\end{array}$ & \\
\hline & $\begin{array}{l}\text { 3. Unfavorable gauge } \\
\text { position } \rightarrow \text { low visibility }\end{array}$ & $\begin{array}{l}\text { 3. Change positions of } \\
\text { the gauges }\end{array}$ & \\
\hline & $\begin{array}{l}\text { 4. Heavy weight } \rightarrow \text { hard } \\
\text { to handle }\end{array}$ & $\begin{array}{l}\text { 4. Apply a new PTFE } \\
\text { brush }\end{array}$ & \\
\hline ts & $\begin{array}{l}\text { 5. Adhesion of coating } \\
\text { material at U-shaped } \\
\text { tube } \rightarrow \text { hard to wash and } \\
\text { replace }\end{array}$ & $\begin{array}{l}\text { 5. Apply new PTFE } \\
\text { tubes }\end{array}$ & \\
\hline
\end{tabular}

\subsection{Test Procedure and Measurement}

\subsubsection{Coating Procedure}

Figure 6 describes the detailed procedure for the indoor experiments. First of all, the epoxy resins and equipment were prepared. An SS400 plate was mounted in the water bath, and each coating material was applied to the plate underwater with the prepared equipment. Then, the coated plate was moved to the curing bath. After each curing time, the specimen was taken out from the curing bath, and the thickness and bond strength of the coating were measured.
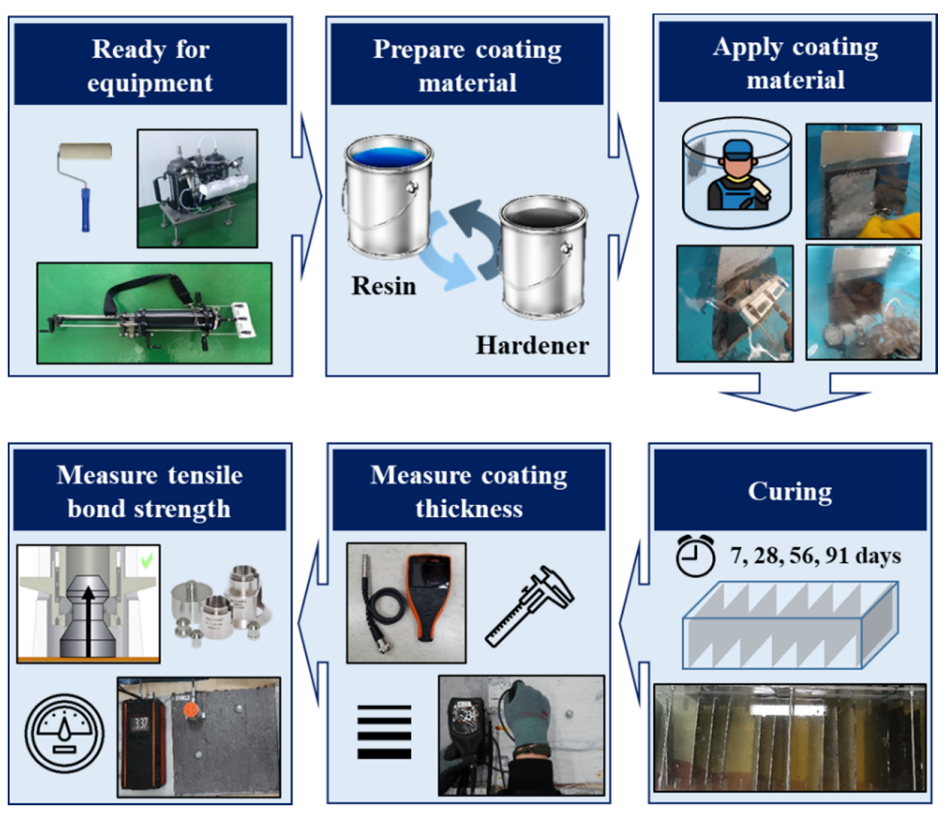

Figure 6. Coating procedure (Adapted with permission from Ref. [12] 2019 by Kim et al., MDPI). 


\subsubsection{Measurement}

After each curing period, coating steel plates were removed from the water, and three dollies were attached to each specimen, as shown in Figure 7. The measurement method and equipment types for the thickness and bond strength were the same as those used in the previous study, as shown in Figure 8. An Elcometer F510-50S (Manchester, UK) was used to measure the bond strength, where the attached dolly was pulled off the specimen at a speed of $0.10 \mathrm{MPa} / \mathrm{s}$. The thickness of the coating was measured with the Elcometer A456CFBI1, which uses a nondestructive method based on the magnetism of the object. The thickness was measured in four directions (up, down, left, and right) based on the dolly position. Then, the bond strength was measured.

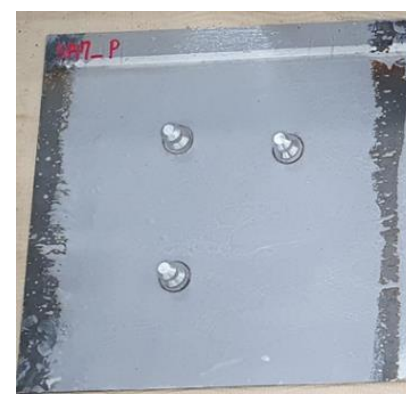

(a)

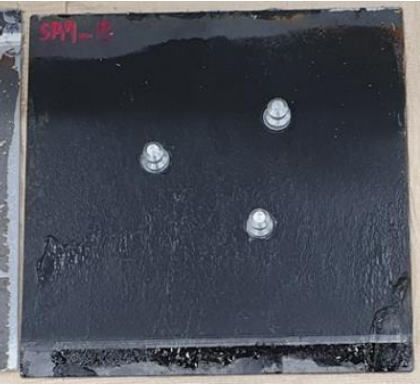

(b)

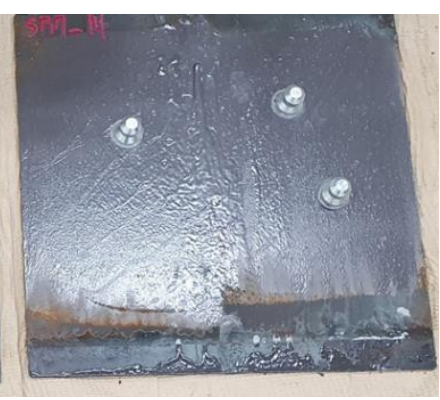

(c)

Figure 7. Coated SS400 plates and attached dollies (a) M1, (b) M2, and (c) M3.
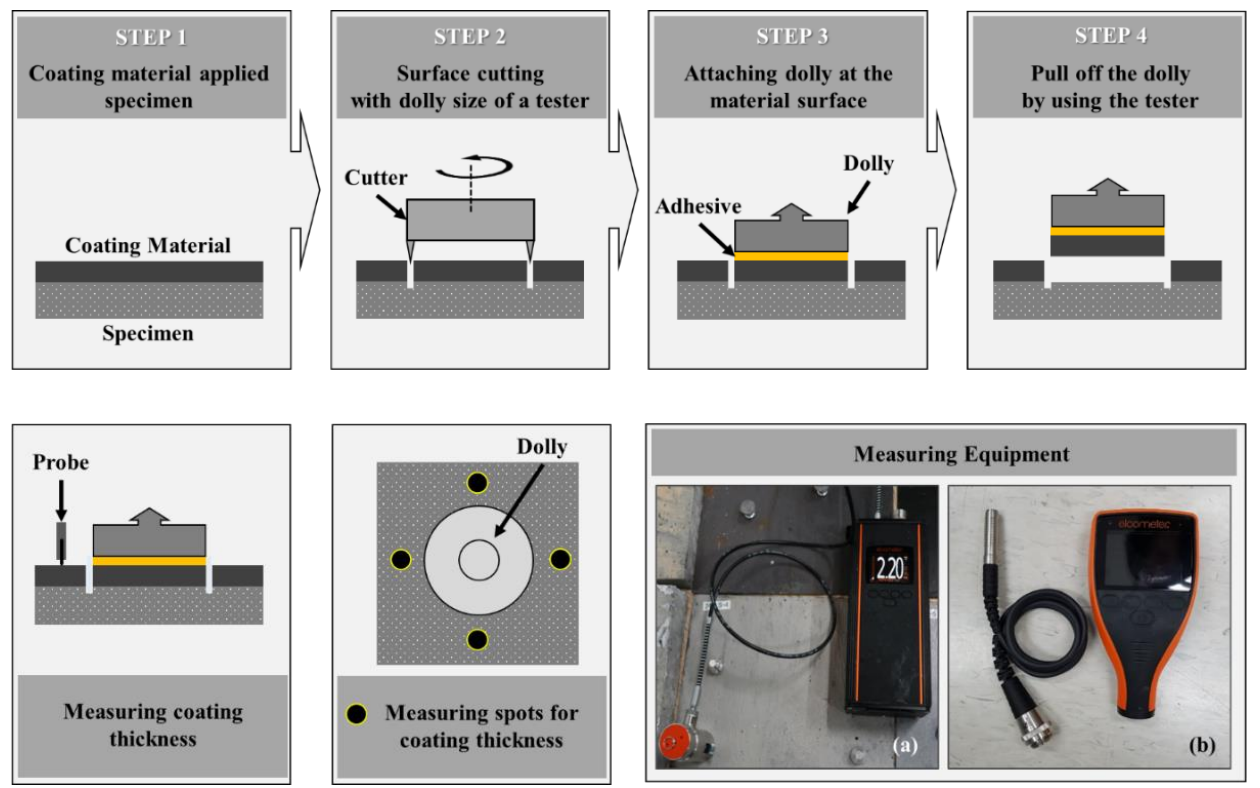

Figure 8. Measurements of the bond strength and coating thickness (a) pull-off adhesion gauge and (b) coating thickness gauge (Adapted with permission from Ref. [12] 2019 by Kim et al., MDPI).

Scanning electron microscopy (SEM) images were taken at 1000× magnification with an EM-30AX manufactured by COXEM, Daejeon, Korea, and used to analyze the interfacial bond between the applied coating and substrate. The steel specimen was made of SS400 with dimensions of $100 \mathrm{~mm} \times 100 \mathrm{~mm} \times 3 \mathrm{~mm}$. To prepare the specimens for SEM, the appropriate side of the coated specimen was selected and cut with a high-speed saw. Each specimen was cold-mounted with an adhesive consisting of an epoxy resin and hardener (mixed at a weight ratio of 100:12). The specimens were cured for $8 \mathrm{~h}$ in a $32 \mathrm{~mm}$-diameter mounting cup and polished for $5 \mathrm{~min}$ with a 600-grit abrasive. Polishing was performed in four steps: $9 \mu \mathrm{m}$ polishing for $10 \mathrm{~min}, 3 \mu \mathrm{m}$ polishing for $5 \mathrm{~min}, 1 \mu \mathrm{m}$ polishing for $5 \mathrm{~min}$, and finally $0.05 \mu \mathrm{m}$ polishing for $3 \mathrm{~min}$. 


\section{Results and Discussion}

\subsection{Effects of Epoxy Resin on Measured Thickness and Bond Strength}

Figure 9 shows the effect of different epoxy resins on the measured thickness and it can be seen that the values are varied depending on both coating equipment and exposure conditions. Averaged thickness values for the M1, M2, and M3 measured in the actual marine environment were $62 \%, 54 \%$, and $22 \%$ higher compared to those in the tap water condition, respectively. The M3 coating applied to SS400 plates with using EQ_H showed the highest thickness of $175.4 \mu \mathrm{m}$ in the laboratory condition (tap water) as shown in Figure 9a. The reason for the different results in thickness measured in the marine environment might be due to the relatively poor working condition caused by the present of tidal currents and limited working time. The influence of epoxy resin types on the thickness was not obvious.

(a)

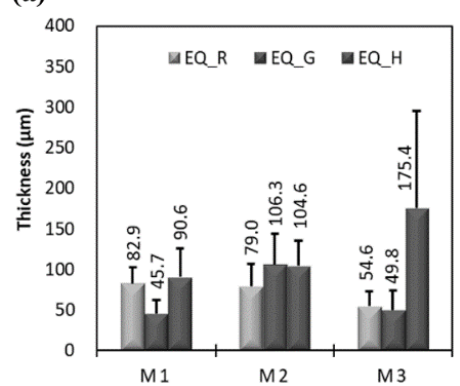

(b)

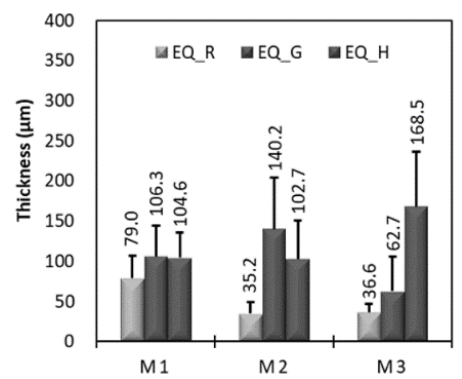

(c)

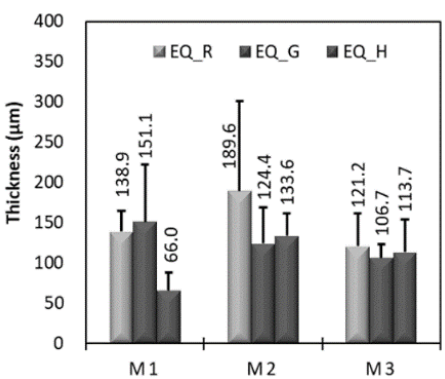

Figure 9. Measured coating thickness: (a) laboratory condition (tap water), (b) laboratory condition (sea water), and (c) marine environment.

Figure 10 illustrates the effects of epoxy resin types on the measured bond strength and the values were recorded on the graphs. Measured strength values varied between 1.10 and $3.30 \mathrm{MPa}$ and changed significantly depend on curing environment and coating equipment. As illustrated in Figure 10, bond strengths measured in the marine environment were $28 \%$ and $33 \%$ lower compared to other two exposure conditions (tap water and seawater), respectively, and this might be attributed to uncontrolled conditions (temperature fluctuation and salinity). M3 coating showed the better bond performance compared to other coatings regardless of exposure conditions and coating equipment, and this is consistent with our previous research [11]. Figure 11 depicts some representative SEM images taken at 7 and 91 days of exposure time to see the time-dependent change in interfacial bond between SS400 plates and coatings. After 7 days of curing, the adhesion of the coating material was very neat and uniform in the tap water environment. However, cracks were partially observed after 91 days. This tendency is similar to the decrease in bond strength over time. Overall, it can be concluded that the marine environment contributed to a thicker coating and lower bond strength and this will be discussed further in the following section.

(a)

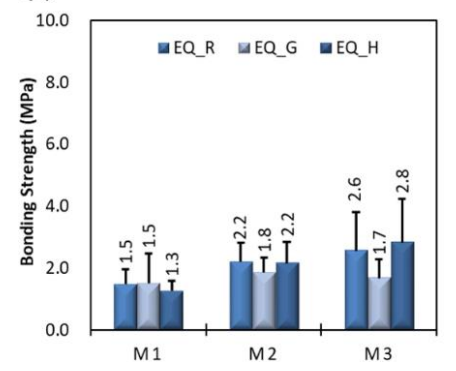

(b)

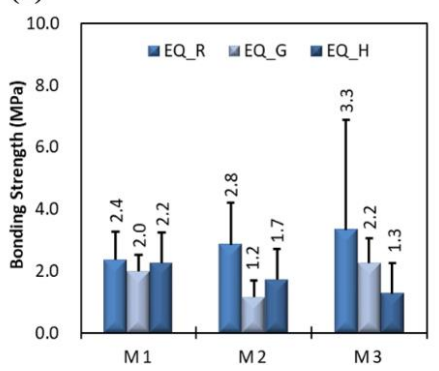

(c)

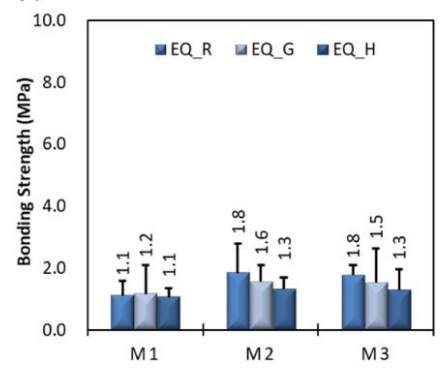

Figure 10. Measured pull-off bond strength: (a) laboratory condition (tap water), (b) laboratory condition (sea water), and (c) marine environment. 


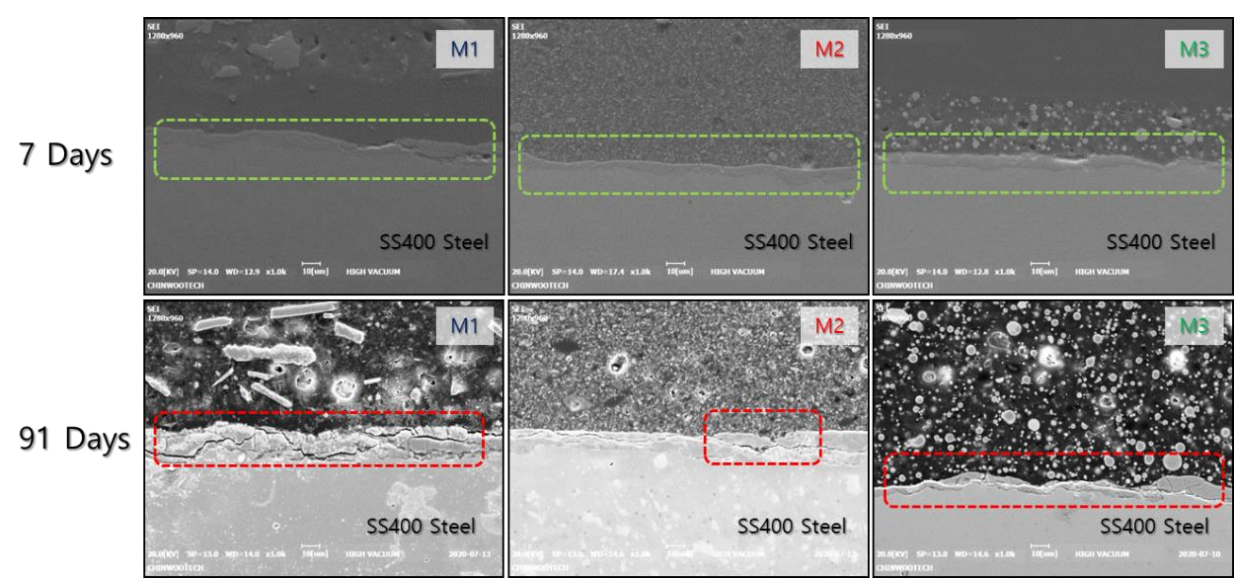

Figure 11. Representative SEM images of the interfacial zone between SS400 plates and epoxy resins at 7 and 91 days.

\subsection{Effects of Exposure Condition on Measured Thickness and Bond Strength}

The effects of different exposure conditions on the thickness and bond strength were examined. Figures 12-14 show the effect of different conditions on the bond strength and thickness in tap water, seawater, and marine environment conditions, respectively. Each graph exhibits the slope of the decreasing in bond strength that varied for each condition. The bond strength decreased more steeply in the indoor environments compared to the marine environment. The average bond strength was slightly higher for the indoor environments at 7 days, but it was similar for all environmental cases after 91 days. Specifically, M3 coating exhibited the highest bond strength in tap water between 7 and 56 days, while it showed a rapid reduction in bond strength with increasing time. M1 coating was expected to have a better bond than M2 based on the previous studies [11,12]. However, M1 coating showed the lowest bond in tap water and this might be due to the different coating conditions (temperature and humidity) and/or coating method. No significant differences in measured bond strength and thickness values were confirmed between the tap water and seawater conditions. Furthermore, thickness in seawater conditions was greatly varied and this might be due to the presence of salinity in seawater. In the actual marine environment, lower bond strength and higher thickness values were confirmed compared to two other conditions. Furthermore, all measured values were greatly varied compared to constant laboratory conditions. Overall, it can be concluded that M2 and M3 coatings performed better compared to M1 coating in all exposure conditions investigated in this study.

(a)

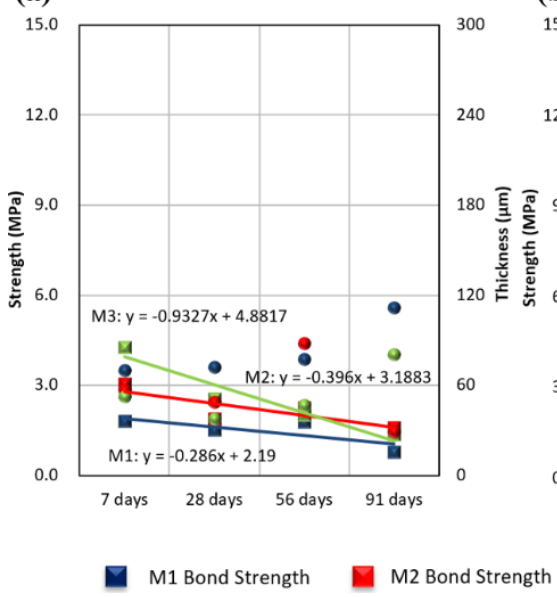

(b)

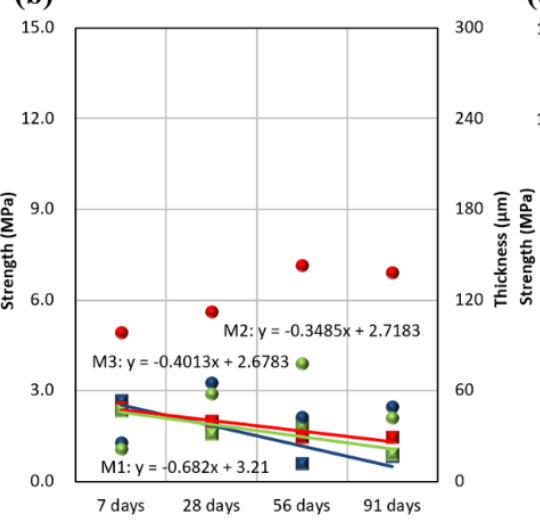

(c)

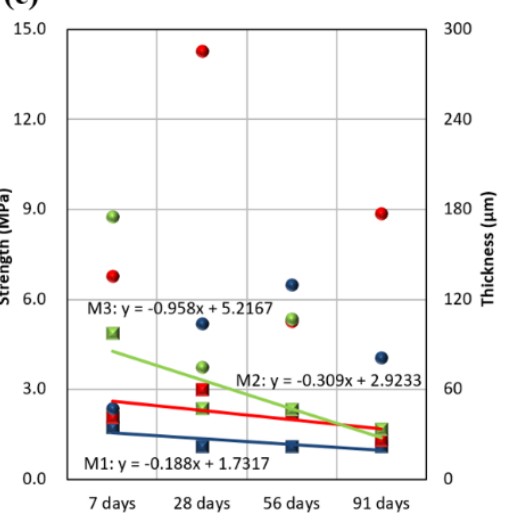

M3 Bond Strength

M1 Thickness

M2 Thickness M3 Thickness

Figure 12. Changes in bond strength and thickness according to exposure periods (tap water condition): (a) EQ_R, (b) EQ_G, and (c) EQ_H. 
(a)

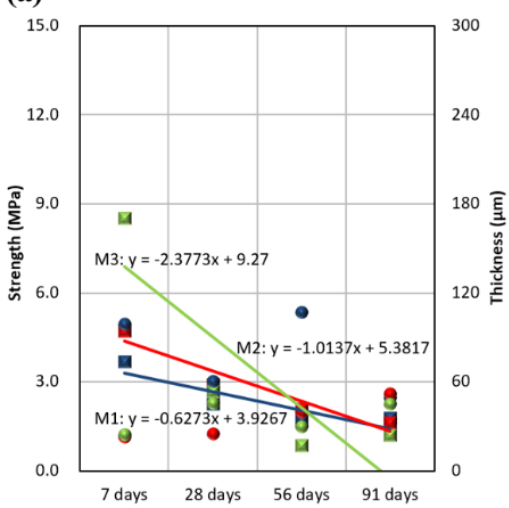

M1 Bond Strength (b)

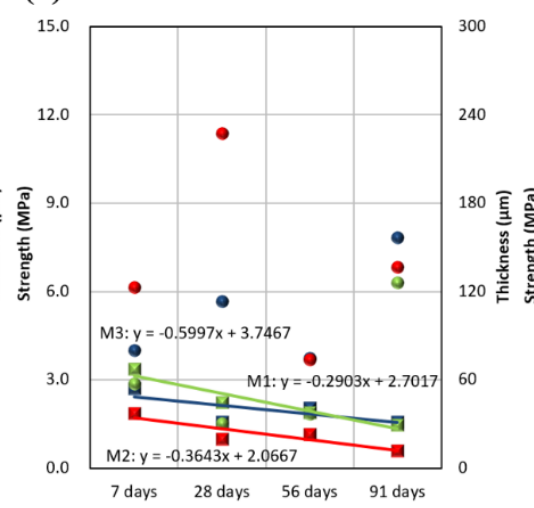

M1 Thickness (c)

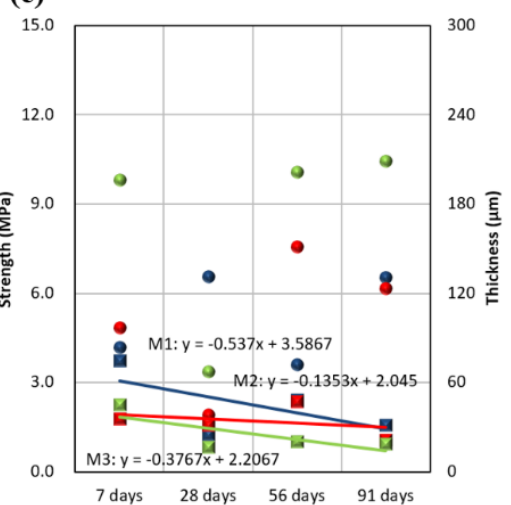

Figure 13. Changes in bond strength and thickness according to exposure periods (seawater condition): (a) EQ_R, (b) EQ_G, and (c) EQ_H.

(a)

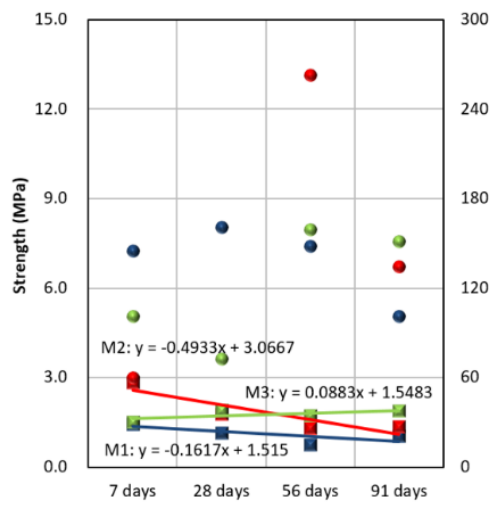

(b)

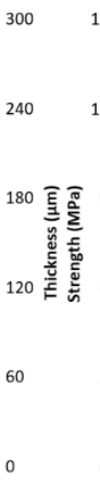

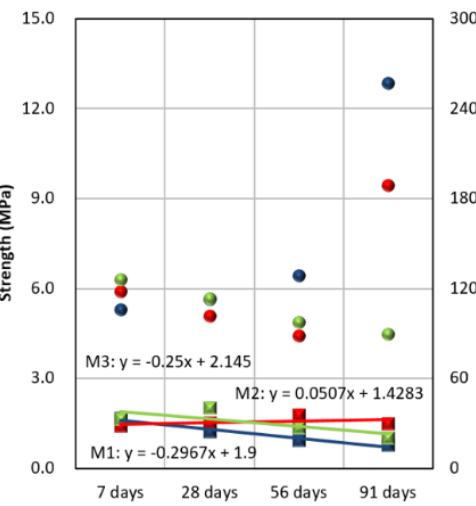

(c)

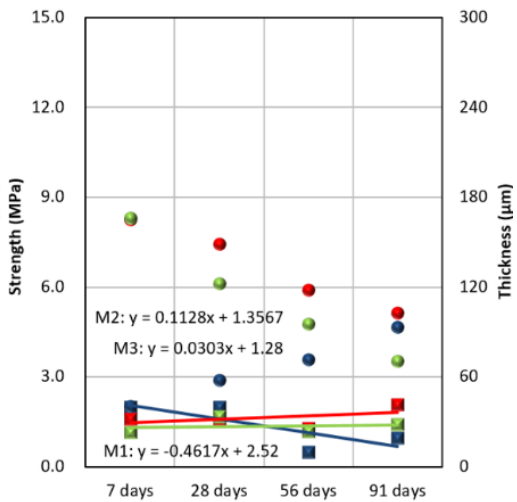

M1 Bond Strength

M2 Bond Strength

M3 Bond Strength

M1 Thickness

M2 Thickness M3 Thickness

Figure 14. Changes in bond strength and thickness according to exposure periods (actual marine environment): (a) EQ_R, (b) EQ_G, and (c) EQ_H.

Figure 15 summarizes the relationships between the thickness and bond strength according to the exposure conditions and coating materials. Bond strengths ranged from 0.1 to $10.0 \mathrm{MPa}$ when thickness value was less than $100 \mu \mathrm{m}$. It can be seen that the M3 coating using EQ_R or EQ_G showed the good performance compared to other relationships. In addition, thicknesses for M3 coating were stable in the actual marine environment regardless of type of coating equipment. The experimental results presented in this paper indicate that a thinner coating thickness should be made in order to achieve a higher bond strength. 

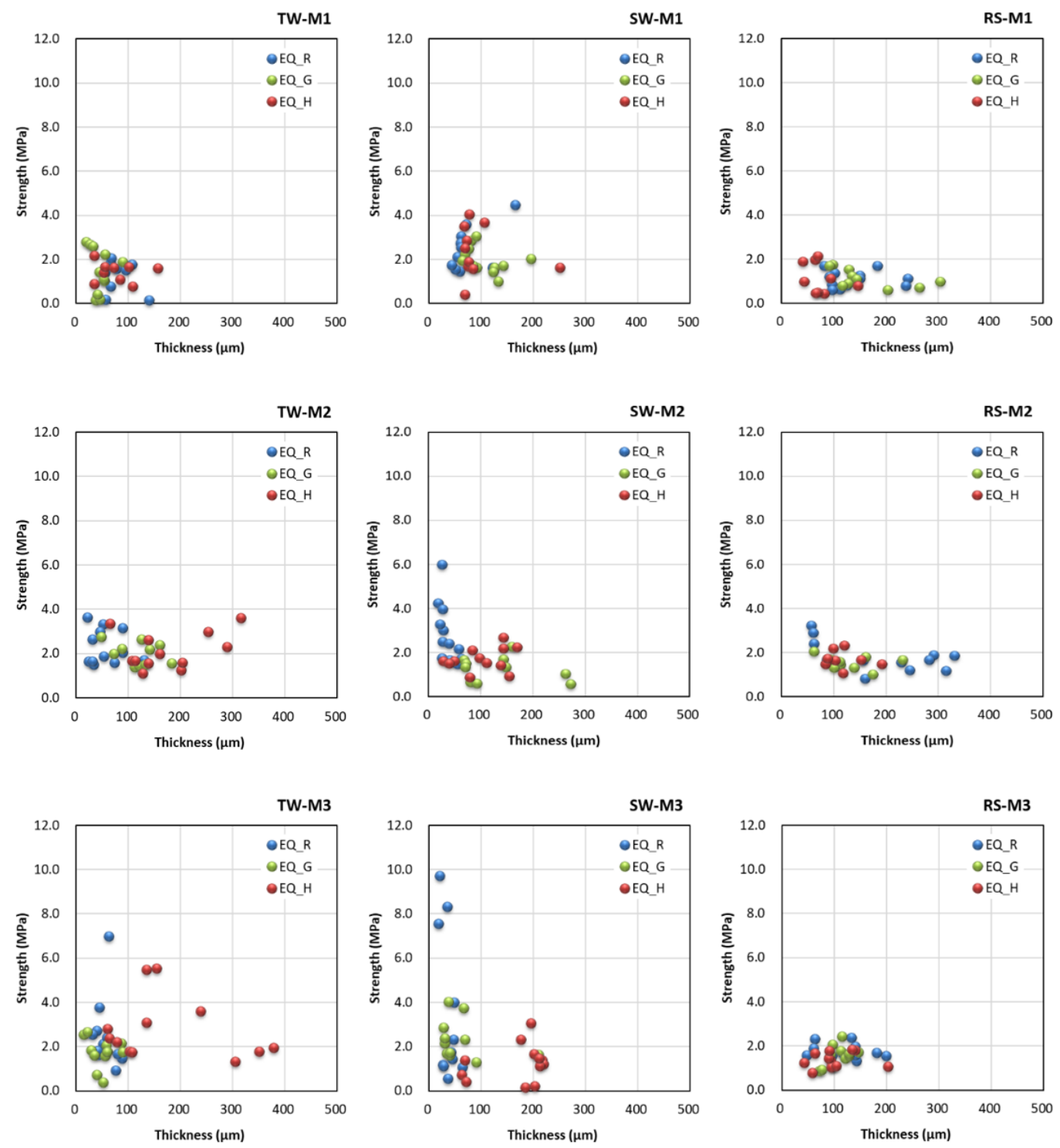

Figure 15. Relationships between measured thickness and bond strength values.

In addition, there were few external forces applied to the operator during the indoor experiment, so the coating could be applied relatively easily. However, the operator should move continuously while applying the coating. In addition, a separate container is required to supply the coating material, which must be applied directly to EQ_R underwater. Therefore, its functionality inevitably deteriorates in a real sea environment. The improved EQ_G and EQ_H were confirmed to be more convenient to use in the real sea environment than EQ_R because the coating material was supplied directly to the brush. For EQ_G, the results showed a similar pattern in all environments. EQ_H performed better in the real sea environment than in the indoor environments. This was attributed to the self-weight and buoyancy of EQ_H, which made it easier to use in the real sea environment.

\subsection{Effects of Exposure Period on Measured Thickness and Bond Strength}

Figures 12-14 above express the time-dependent changes in bond strength and coating thickness according to the exposure periods. The curing time was set to a minimum of 7 days and maximum of 91 days so that the coating materials would be sufficiently cured, and the bond strength was measured at each curing time. Overall, the bond strength tended to decrease as the exposure time increased. Each value represents the average from three dollies. Each experiment was based on a selected equipment 
type, not coating material. In other words, one equipment type was used to apply multiple coating materials, rather than multiple equipment types being used to apply one coating material. Each graph shows the results of three coating materials applied in sequence by the same operator using the same equipment at similar times. Among the equipment types, EQ_H had a large standard deviation; among the materials, M2 coating had a large standard deviation. In the previous study, the standard deviation of the coating thickness was relatively large according to the equipment type and coating material [12]. In this study, the standard deviation was significantly reduced under the same conditions used previously.

\subsection{Effects of Coating Equipment on Measured Thickness and Bond Strength}

The averaged bond strength and standard deviation for each type of equipment were 2.23 MPa and 1.46 for EQ_R, 1.67 MPa and 0.62 for EQ_G, and 1.69 MPa and 0.93 for EQ_H, respectively. The differences in the averaged coating thickness between each type of equipment were not significant compared to a previous study [12]. For EQ_R, the average thickness was $90 \mu \mathrm{m}$, which is similar to our previous results [12]. However, it increased from $40 \mu \mathrm{m}$ to $90 \mathrm{~mm}$ for EQ_G. For EQ_H, the averaged thickness decreased by a third from 380 to $120 \mu \mathrm{m}$ with the improved equipment. EQ_H had a greater standard deviation than EQ_R and RQ_G in both the indoor and real sea tests. This suggests that EQ_H is less convenient to use for coating than the other two equipment types. This may be attributed to the need to adjust two valves for the air and coating material with EQ_H. Overall, however, the standard deviation was less than that in the previous study. This indicates that the applied coating was improved with the newly developed brush. There was no significant difference in the results performed indoors and in the actual marine environment. Thus, a smooth coating can be achieved by using bundles of thin Teflon fibers.

\subsection{Discussion}

The bond strength measured in this study varied from 0.1 to $10.0 \mathrm{MPa}$, and the values were generally lower than those provided from suppliers (see Table 1). These different results can be attributed to the exposure condition and time of measurement. Specifically, the values on the data sheets were measured at conventional atmospheric condition after 1 to 7 days of coating rather than the actual seawater condition with long time exposure. In this regard, this study provides valuable data for the selection and the use of epoxy resins for the surface coating of submerged steel structures. Overall, test results were quite different depending on the exposure conditions and type of epoxy resins, and M3 coating showed the good performance with increased bond and thinner thickness compared to other coatings. EQ_R and EQ_G contributed to a better coating compared to that of EQ_H while EQ_H was convenient to handle underwater conditions. M1 coating was originally expected to show the better performance. However, measured strength and thickness did not satisfy the specific requirement. It should be noted that the three materials investigated in this study were chosen based on the measured bond strength values (see Figure 16). In Figure 16, C1, C2, and C4 correspond to M3, $\mathrm{M} 2$, and M1, respectively.

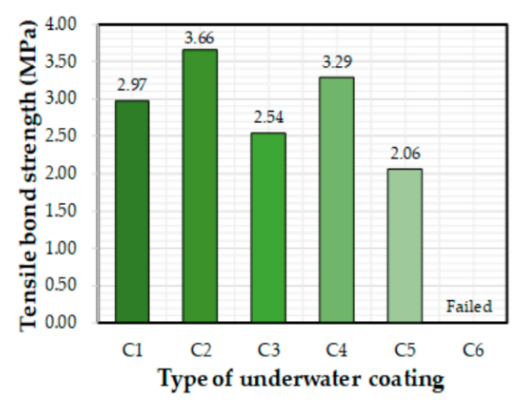

Figure 16. Bond strengths after $72 \mathrm{~h}$ of tap water exposure (coated with conventional roller) (Adapted with permission from Ref. [11] 2019 by Won et al., MDPI). 
In this study, it was confirmed that the exposure condition and coating equipment had a significant influence on the adhesive properties and uniform coating thickness. Therefore, further studies might be important to reduce the influence of severe exposure conditions and to improve the interfacial bond between applied epoxy resins and targeted steel structures. The present results were obtained from one limited location. Further experimental studies are, however, necessary to make comparisons between the tests conducted in the laboratory and those carried out in severe marine conditions with fast tidal currents.

\section{Conclusions}

An experimental program was set up to clarify the effect of different exposure conditions on the interfacial bond between steel plates and applied epoxy resin coatings during at early ages. Three coating equipment were tested indoors and in an actual marine environment with three coating materials. The curing time varied from 7 to 91 days, and the thickness and bond strength of the coating material were measured after each curing time. The results for the coating material, equipment, and curing time were analyzed, and the performances of the improved equipment types were compared with those in the previous study. The following conclusions can be drawn:

1. Even when the initial bond strength was high, the strength was confirmed to weaken with increased time. This trend was the same under all environmental conditions. The initial bond strength was higher in the indoor tests than in the real sea test, but all bond strengths were similar after 91 days. In addition, the bond strength decreased more over time in the indoor tests than in the real sea test.

2. No significant correlation between the measured coating thickness and bond strength was observed.

3. Overall, the improved equipment types reduced the standard deviation of the coating thickness compared to the results of the previous study. The functionality of the equipment improved because of the reduced self-weight, and the coating thickness was more uniform owing to the improved brush.

4. The functionality of the equipment types differed according to the environmental conditions. EQ_R had excellent functionality indoors, but the developed equipment types were more convenient to use in the real sea test. This was attributed to the latter supplying the coating material to the brush directly.

In summary, the improvements to the equipment types were confirmed to be effective to some degree. The difficulties with underwater coating were successfully solved by the development of a new Teflon brush that made it possible to realize a constant coating thickness. In addition, the improved equipment was more convenient to use compared to a conventional roller under an actual marine environment such as in underwater conditions. However, the equipment types have limited working areas and working times because the coating material needs to be stored in a tank after the main resin and hardener are mixed. Therefore, the improved equipment types are suitable for local coating of structures. In practice, real offshore structures need to be coated over a large area, so a longer working time may be required. Future research will need to focus on devising a method for supplying large amounts of the base resin and hardener that can be mixed just before being sprayed by the outlet of the equipment. Coating materials also need further development.

Author Contributions: Conceptualization, M.O.K.; methodology, M.O.K.; validation, S.K., H.H., S.I.C. and M.O.K.; investigation, S.K.; data curation, S.K., H.H., J.K.P., S.P. and S.I.C.; writing-original draft preparation, S.K.; writing—review and editing, M.O.K.; visualization, S.K.; supervision, M.O.K.; project administration, M.O.K. All authors have read and agreed to the published version of the manuscript.

Funding: This research work was supported by the "Development of application technologies for ocean energy and harbor and offshore structures (KIOST Project Number: PE99831)".

Conflicts of Interest: The authors declare no conflict of interest. 


\section{References}

1. Jiang, D.; Tan, K.H.; Wang, C.M.; Ong, K.C.G.; Bra, H.; Jin, J.; Kim, M.O. Analysis and design of floating prestressed concrete structures in shallow waters. Mar. Struct. 2018, 59, 301-320. [CrossRef]

2. Justnes, H.; Kim, M.O.; Ng, S.; Qian, X. Methodology of calculating required chloride diffusion coefficient for intended service life as function of concrete cover in reinforced marine structures. Cem. Concr. Compos. 2016, 73, 316-323. [CrossRef]

3. Kim, M.O.; Bordelon, A.; Lee, M.K.; Oh, B.H. Cracking and failure of patch repairs in RC members subjected to bar corrosion. Constr. Build. Mater. 2016, 107, 255-263. [CrossRef]

4. Andrade, C. Calculation of chloride diffusion coefficients in concrete from ionic migration measurements. Cem. Concr. Res. 1993, 23, 724-742. [CrossRef]

5. Kim, M.O.; Qian, X.; Lee, M.K.; Park, W.S.; Jeong, S.T.; Oh, N.S. Determination of structural lightweight concrete mix proportion for floating concrete structures. J. Korean Soc. Coast. Ocean Eng. 2017, 29, 315-325. [CrossRef]

6. Pan, X.; Shi, Z.; Shi, C.; Ling, T.; Li, N. A review on concrete surface treatment Part I: Types and mechanisms. Constr. Build. Mater. 2017, 132, 578-590. [CrossRef]

7. Basheer, L.; Cleland, D.; Long, A. Protection provided by surface treatments against chloride induced corrosion. Mater. Struct. 1998, 31, 459-464. [CrossRef]

8. Christodoulou, C.; Goodier, C.I.; Austin, S.A.; Webb, J.; Glass, G.K. Long-term performance of surface impregnation of reinforced concrete structures with silane. Constr. Build. Mater. 2013, 48, 708-716. [CrossRef]

9. Kim, M.O.; Jeong, Y.; Kang, S.H.; Moon, J.; Yi, J.H. Tensile bond characteristics between underwater coating materials and concrete substrate. J. Korean Soc. Coast. Ocean Eng. 2018, 30, 298-305. [CrossRef]

10. Hammer, P.; dos Santos, F.C.; Cerrutti, B.M.; Pulcinelli, S.H.; Santilli, C.V. Carbon nanotube-reinforced siloxane-PMMA hybrid coatings with high corrosion resistance. Prog. Org. Coat. 2013, 76, 601-608. [CrossRef]

11. Won, B.; Kim, M.O.; Park, S.; Yi, J. Effects of water exposure on the interfacial bond between an epoxy resin coating and a concrete substrate. Materials 2019, 12, 3715. [CrossRef] [PubMed]

12. Kim, S.; Hong, H.; Han, T.H.; Kim, M.O. Early-age tensile bond characteristics of epoxy coatings for underwater applications. Coatings 2019, 9, 757. [CrossRef]

13. Global Wind Energy Council, Global offshore Wind Report 2020. Available online: https://www.rivieramm. com/news-content-hub/news-content-hub/offshore-wind-to-surge-to-more-than-234-gw-by-2030-60496 (accessed on 2 October 2020).

14. Stehly, T.; Beiter, P. 2018 Cost of Wind Energy Review; Technical Report; NREL: Golden, CO, USA, 2019.

15. Bugnot, A.B.; Mayer-Pinto, M.; Airoldi, L.; Heery, E.C.; Johnston, E.L.; Critchley, L.P.; Strain, E.M.A.; Morris, R.L.; Loke, L.H.L.; Bishop, M.J.; et al. Current and projected global extent of marine built structures. Nat. Sustain. 2020. [CrossRef]

16. Kanwal, S.; Ali, N.Z.; Hussain, R.; Shah, F.U.; Akhter, Z. Poly-thiourea formaldehyde based anticorrosion marine coatings on type 304 stainless steel. J. Mater. Res. Technol. 2020, 9, 2146-2153. [CrossRef]

17. Ates, M. A review on conducting polymer coatings for corrosion protection. J. Adhes. Sci. Technol. 2016, 30, 1510-1536. [CrossRef]

18. Abbas, M.; Shafiee, M. An overview of maintenance management strategies for corroded steel structures in extreme marine environments. Mar. Struct. 2020, 71, 102718. [CrossRef]

19. Nazarov, A.; Bozec, N.L.; Thierry, D. Scanning Kelvin probe assessment of steel corrosion protection by marine paints containing Zn-rich primer. Prog. Org. Coat. 2018, 125, 61-72. [CrossRef]

20. Zhao, Z.; Tang, J.; Tariq, N.H.; Wang, J.; Cui, X.; Xiong, T. Microstructure and corrosion behavior of cold-sprayed Zn-Al composite coating. Coatings 2020, 10, 931. [CrossRef]

21. Aggoun, K.; Chaal, L.; Creus, J.; Sabot, R.; Saidani, B.; Jeannin, M. Marine corrosion resistance of $\mathrm{CeO}_{2} / \mathrm{Mg}(\mathrm{OH})_{2}$ mixed coating on a low alloyed steel. Surf. Coat. Technol. 2019, 372, 410-421. [CrossRef]

22. Ibrahim, M.; Kannan, K.; Parangusan, H.; Eldeib, S.; Shehata, O.; Ismail, M.; Zarandah, R.; Sadasivuni, K.K. Enhanced corrosion protection of epoxy/ZnO-NiO nanocomposite coatings on steel. Coatings 2020, 10, 783. [CrossRef]

23. Singh, A.A.M.M.; Franco, P.A.; Binoj, J.S. Enhancement of corrosion resistance on plasma spray coated mild steel substrate exposed to marine environment. Mater. Today Proc. 2019, 15, 84-89. [CrossRef] 
24. Sambyal, P.; Ruhi, G.; Dhawan, S.K.; Bisht, B.M.S.; Gairola, S.P. Enhanced anticorrosive properties of tailored poly(aniline-anisidine)/chitosan/ $\mathrm{SiO}_{2}$ composite for protection of mild steel in aggressive marine conditions. Prog. Org. Coat. 2018, 119, 203-213. [CrossRef]

25. Kamburova, K.; Boshkova, N.; Tabakova, N.; Boshkov, N.; Radeva, T.S. Application of polymeric modified polyaniline-silica particles for improved corrosion resistance of hybrid zinc coatings. Colloids Surf. A 2020, 592, 124546. [CrossRef]

26. Mohan, S.; Nair, S.S.; Ajay, A.V.; Saravanan, M.S.S.; Vishnu, B.R.; Sivapirakasam, S.P.; Surianarayann, M. Corrosion behaviour of $\mathrm{ZrO}_{2}-\mathrm{TiO}_{2}$ nano composite coating on stainless steel under simulated marine environment. Mater. Today Proc. 2020, 27, 2492-2497. [CrossRef]

27. Zhai, Y.; Pan, K.; Zhang, E. Anti-corrosive coating of carbon-steel assisted by polymer-camphorsulfonic acid embedded within graphene. Coatings 2020, 10, 879. [CrossRef]

28. Acero-Gutierrez, A.K.; Perez-Rlores, A.L.; Gorinez-Salcedo, J.G.; Moreno-Palmerin, J.; Morales-Ramirez, A.J. Corrosion protection of A36 Steel with $\mathrm{SnO}_{2}$ nanoparticles integrated into $\mathrm{SiO}_{2}$ coatings. Coatings 2020, 10, 385. [CrossRef]

29. Verma, C.; Olasunkanmi, L.O.; Akpan, E.D.; Quraishi, M.A.; Dagdag, O.; El Gouri, M.; Sherif, E.M.; Ebenso, E.E. Epoxy resins as anticorrosive polymeric materials: A review. React. Funct. Polym. 2020, 156, 104741. [CrossRef]

30. Atta, A.M.; Al-Hodan, H.A.; Hameed, R.S.A.; Ezzat, A.O. Preparation of green cardanol-based epoxy and hardener as primer coatings for petroleum and gas steel in marine environment. Prog. Org. Coat. 2017, 111, 283-293. [CrossRef]

Publisher's Note: MDPI stays neutral with regard to jurisdictional claims in published maps and institutional affiliations. 